\title{
Sex and gender issues in competitive sports: investigation of a historical case leads to a new viewpoint
}

\author{
Kaye N Ballantyne, ${ }^{1}$ Manfred Kayser, ${ }^{1}$ J Anton Grootegoed ${ }^{2}$
}

- Additional data are published online. To view these files please visit the journal online (http://bjsm.bmi.com/ content/46/8.toc).

1 Department of Forensic Molecular Biology, Erasmus MC - University Medical Center Rotterdam, Rotterdam, The Netherlands ${ }^{2}$ Department of Reproduction and Development, Erasmus MC - University Medical Center Rotterdam, Rotterdam The Netherlands

\section{Correspondence to} J Anton Grootegoed, Department of Reproduction and Development, Erasmus MC - University Medical Center Rotterdam, Room Ee 09-71, P0 Box 2040, 3000 CA Rotterdam, The Netherlands; j.a.grootegoed@erasmusmc.nl

Accepted 28 March 2011 Published Online First 3 May 2011

\section{(6) UNLOCKED}

This paper is freely available online under the BMJ Journals unlocked scheme, see http:// bjsm.bmj.com/info/unlocked.dtl

\section{ABSTRACT}

Based on DNA analysis of a historical case, the authors describe how a female athlete can be unknowingly confronted with the consequences of a disorder of sex development resulting in hyperandrogenism emerging early in her sports career. In such a situation, it is harmful and confusing to question sex and gender. Exposure to either a low or high level of endogenous testosterone from puberty is a decisive factor with respect to sexual dimorphism of physical performance. Yet, measurement of testosterone is not the means by which questions of an athlete's eligibility to compete with either women or men are resolved. The authors discuss that it might be justifiable to use the circulating testosterone level as an endocrinological parameter, to try to arrive at an objective criterion in evaluating what separates women and men in sports competitions, which could prevent the initiation of complicated, lengthy and damaging sex and gender verification procedures.

\section{INTRODUCTION}

In 1949, the Dutch track athlete Foekje Dillema (1926-2007) came to prominence on the world athletic stage. She started to rival Fanny BlankersKoen, the world-famous Dutch track athlete who won four gold medals during the 1948 Summer Olympics in London and was elected Female Athlete of the Century by the International Association of Athletics Federations (IAAF) in 1999. In contrast, Dillema's career was of short duration, with a dramatic ending. In 1950, she was expelled for life by the Royal Dutch Athletics Federation, due to the results of a 'sex test', for which details or results were never revealed and no records are available. Her 1950 national record of $24.1 \mathrm{~s}$ for the $200 \mathrm{~m}$, which she took from Fanny Blankers-Koen, was erased, and only after her death 57 years later was she reinstated by the Royal Dutch Athletics Federation (figure 1). ${ }^{1}$

The verification of the sex of athletes has been an issue for many decades. It should be noted that reports and reviews on this topic refer to gender verification, rather than sex verification. ${ }^{2-4}$ However, what counts in competitive sports is a person's sex characteristics. Trying to avoid the word sex, given its charged nature, can only cause confusion. ${ }^{6}{ }^{6}$ Herein, we will use the term sex for the biological and physiological characteristics that define men and women, as compared to gender and gender identity in reference to the socially and individually perceived sexual identity of an individual from birth to puberty and adulthood. 578

Sex verification in 1950 was based solely on physical examination, predating hormone assays or sex chromosome analysis. Following discovery of the Barr body in female cells in 1949, it took some 12 years before it was known that this body represents an inactivated $\mathrm{X}$ chromosome ${ }^{9}$; from the late 1960s its detection was used in sex verification tests in the context of sports competitions. ${ }^{2-4}$ Subsequent tests focused on the male-specific region of the $\mathrm{Y}$ chromosome, particularly the male sex determining $S R Y$ gene. ${ }^{10}$ However, opposition to sex verification for female athletes with laboratory-based genetic testing developed in the 1970s and 1980s, because these tests did not encompass the complexities of disorders of sex development (DSDs). Since the 2000 Summer Olympics, questioned sex and gender is evaluated on a case-by-case basis by a team of specialists in the areas of endocrinology, genetics, gynaecology and psychology. ${ }^{3-5}$

To broaden the perspective on sportswomen confronted with questioned sex characteristics, we have investigated the case of Foekje Dillema, with informed consent from her heirs, by means of DNA analysis of samples from worn clothing. Appreciating the nature of the samples tested, we applied DNA methodology and lab quality standards used in human forensics. Our DNA analysis indicates that Foekje Dillema had a 46,XX/46,XY mosaic condition with a rare origin, which we interpret as leading to hyperandrogenism from her puberty. Based on this historical case we discuss that, if a sportswoman is confronted with signs of a DSD early in her sports career, it is harmful and confusing to question such a person's sex and gender. Rather, we suggest that it is necessary to try to arrive at an objective criterion in evaluating what separates women and men in sports competitions.

\section{RECONSTRUCTION OF A HISTORICAL CASE}

From the combined genotyping and DNA quantification results, we conclude that Foekje Dillema was a $46, \mathrm{XX} / 46, \mathrm{XY}$ mosaic, with equal numbers of both genetic cell types at least in her skin (online supplementary data). In the fetal gonads of a 46,XX/46,XY mosaic, the tissue ratio of $\mathrm{XX}: \mathrm{XY}$ cells will push the bipotential gonads to become either ovaries or testes, or both. A preponderance of 46,XX cells in fetal gonads can 


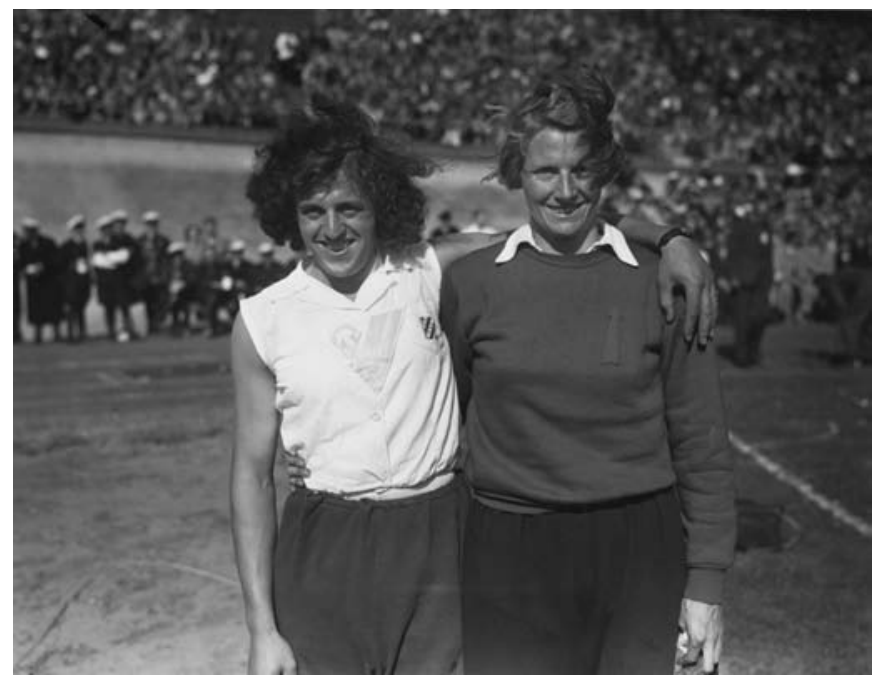

Figure 1 Foekje Dillema (in white shirt on the left) together with Fanny Blankers-Koen, on the Olympic Day, 18 June 1950, in the Olympic Stadium, Amsterdam, when 60000 spectators witnessed Dillema winning the $200 \mathrm{~m}$ in $24.1 \mathrm{~s}$, in a race in which BlankersKoen did not participate. ${ }^{1}$ Photo: Ben van Meerendonk (collection International Institute of Social History, Amsterdam).

lead to the development of ovaries, but with some 46,XY testis tissue present in one or both of these ovaries. Such an ovotestis condition, which can also occur in the form of a complete ovary and a complete testis on either side, has been referred to with the term true hermaphroditism. ${ }^{11} 12$ The most common karyotype found in true hermaphroditism is $46, \mathrm{XX}$, followed by $46, \mathrm{XX} / 46, \mathrm{XY}$ chimerism and mosaicism. ${ }^{12} \mathrm{We}$ would like to emphasise that the term hermaphrodite, as well as other terms such as intersex, need to be replaced by the DSDs classification proposed by consensus in $2006,{ }^{13}$ for the simple reason that the terms hermaphrodite and intersex cannot, and should not, be applied to human individuals. Instead, a true hermaphrodite is correctly referred to as either a female or male individual with ovotesticular DSD. ${ }^{13}$ When ovotestis formation is confined to only one of the gonads, the other gonad and the ovarian part of the ovotestis can function as steroidogenic ovarian tissue. ${ }^{11} 12$ The testicular part of the fetal ovotestis will produce anti-Müllerian hormone, insulin-like factor 3 and testosterone, ${ }^{14}$ acting towards regression of Müllerian ducts, initiation of testis descent and partial virilisation by circulating androgens, respectively, but none of these effects might reach a level where overt fetal virilisation leads to the birth of a boy. Hence, an individual with ovotesticular DSD often is raised as a girl, ${ }^{12}$ and also experiences a female gender identity (described below).

The X:Y ratio in the adult skin, as we obtained from Dillema's clothes, does not provide any information about the ratio in her fetal gonads. However, Foekje Dillema was formally registered as a female at birth, and she was raised as a girl, according to all accounts, including those available from her family. Hence, she is unlikely to have been exposed to a markedly elevated level of testosterone during fetal development. From all available data, including the present DNA evidence, we deduce that Dillema had an ovotesticular DSD with a predominance of ovarian tissue. At the onset of puberty, gonadotropic stimulation of the gonads most likely led to marked activation of steroidogenesis - the production of both oestradiol and testosterone in Dillema's case of ovotesticular DSD. From photographs, it is evident that from puberty she had breast development, but personal accounts also indicate that she showed some facial hair grow th. ${ }^{1}$ Hyperandrogenism from puberty may have contributed to Dillema's athletic performance.

\section{SEX CHARACTERISTICS, GENDER IDENTITY AND TESTOSTERONE}

To have, or not to have, a Y chromosome is the primary decisive factor in human sexual differentiation, but there are exceptions. A prominent example is offered by 46,XY females who have the complete form of androgen insensitivity syndrome (cAIS), when the testes produce testosterone but the body is not able to respond to androgens (testosterone and its more powerful metabolite dihydrotestosterone) due to mutation of the X-encoded androgen receptor. ${ }^{14}$ Consequently, these individuals are born and raised as girls, and have a female gender identity. ${ }^{15} 16$ Action of testosterone through binding to the androgen receptor in the developing fetal brain is the predominant factor in programming human male gender identity, ${ }^{7} 17$ and the female gender identity of 46,XY cAIS women is explained by loss of this androgenic effect. In sports, $46, X Y$ cAIS women can be expected to have a disadvantage compared to $46, \mathrm{XX}$ women with a functional androgen receptor, the latter profiting from stimulation of muscle strength by a low level of circulating testosterone. ${ }^{18} 19$

The biological basis for sex segregation in sports is the consequence of long-term endogenous androgen exposure of men after puberty. ${ }^{20}$ It cannot be excluded that proteins encoded by genes in the male-specific region of the Y chromosome (MSY $)^{21}$ might act together with androgens, widening the physiological gap between women and men. However, such a role for MSY genes will be minor, compared to the predominant role of androgen action. In men, the postpubertal testosterone level is a proven dose-dependent factor when muscle strength and other physiological factors such as the blood haemoglobin level come into play. ${ }^{22}$ A moderate pubertal and postpubertal excess of testosterone in a young woman can give extra muscle development and other signs of hyperandrogenism, but it would be a rude error to even suggest that this would affect her female gender identity.

Competitive athletes exploit fortunate combinations of natural differences in physical and mental personal characteristics, including individual variation of the endogenous testosterone level. The World Anti-Doping Agency states that an athlete's sample will be found positive if the concentration of an endogenous androgenic steroid hormone is above the range normally found in humans, and is not likely consistent with normal endogenous production, unless the elevated concentration of the steroid hormone (or metabolites or markers) is attributable to a physiological or pathological condition. ${ }^{23}$ Strictly speaking, a female athlete is free to benefit from any endogenous source of androgen production. Some female athletes may benefit, probably to a small extent, from increased androgen production originating from a polycystic ovary. ${ }^{19}$ This is viewed as acceptable by the IAAF, who stated that conditions that may provide some advantages but nevertheless are acceptable include congenital adrenal hyperplasia, androgen-producing tumours and an ovulatory androgen excess associated with a polycystic ovary. ${ }^{24}$ According to these regulations, hyperandrogenism caused by ovotesticular DSD would be unacceptable only if sex and gender 


\section{What is already known on this topic}

The complex biology of sex development and its disorders appears to preclude a swift and objective assessment of the eligibility of specific women athletes to compete with other women in competitive sports. Prominent cases, historical and recent, have suffered much confusion and resulted in lengthy procedures, harmful to both the respective athletes and to sports and society at large.

\section{What this study adds}

Describing a historical case, this study puts forward the notion that societal appreciation of sex and gender issues in highly competitive sports requires discussion and understanding of relevant biomedical knowledge. However, the authenticity of an adult individual's sex and gender identity should not be questioned. Rather, there is a need for an objective and relevant criterion in evaluating what separates women and men in sports competitions.

verification would provide evidence that the female athlete in fact is a man. However, we consider it highly unlikely that any individual would aim to participate in sports competitions in conflict with his or her gender identity. There is no problem in sports at large that warrants an examination, initiated by a sports federation, of the authenticity of an adult individual's sex and gender. Hence, there is a need to reconsider the situation.

It might be considered to set an upper limit for the circulating total testosterone level for sportswomen. In cases of cAIS, a high testosterone level would be of no significance. In any other case where the total testosterone level is found to exceed a set limit, causes and consequences need to be resolved before the sportswoman (re-)enters sports competition. This would be ethically justifiable, given the fact that it would be in the individual's own interest to prevent symptoms of long-term hyperandrogenism. The causes and consequences of a high-testosterone level can be dealt with in private, not in public, and, most importantly, without questioning gender identity. The eligibility of Dillema to compete might still be questioned, even today in the current era of improved knowledge about DSDs. However, if an increased endogenous testosterone level would have been detected, possible treatment to lower this level would have cleared the way to competition re-entry, leaving no trace of a sex and gender discussion.

Obviously, a proper definition of an upper limit for the endogenous testosterone level will require a detailed discussion about measurement, metabolites, circadian and other variations, binding proteins, etc. ${ }^{25-27}$ Normative ranges have not been well established, ${ }^{28}$ but available data indicate that a circulating total testosterone level of 3-4 nmol/1 normally will not be exceeded by women of younger age. ${ }^{18} 29$ Leaving all antidoping controls fighting against the use of exogenous androgens in place, ${ }^{30}$ it might be relatively straightforward to arrive at a consensus about the maximally allowed endogenous total testosterone level. With 8-12 nmol/1 total testosterone being considered as a lower limit which may require substitution in men, ${ }^{27}$ and with a reference range of $11-35 \mathrm{nmol} / 1$ for men, ${ }^{31}$ there is a substantial and significant gap in the testosterone level between women and men.

It has been argued that sex is not a binary quantity, with the far-reaching implication that sex segregation in competitive sports is an inconsistent and unjust policy. ${ }^{32}$ This argument was substantiated by pointing out that an individual's genetic background may cause a differential sensitivity to testosterone. Indeed, a genetic polymorphism such as the CAG repeat polymorphism in exon 1 of the gene encoding the androgen receptor affects the sensitivity of cells and tissues to androgens. ${ }^{33}$ However, this effect is likely far too small $^{34}$ to provide any female athlete with an advantage bringing her on par with male athletes. Such a common genetic variation should not be taken into account and does not obstruct the prevailing thought that women and men are to compete separately, meaning that there is a need for a dividing line. ${ }^{35}$ Thinking about a dividing line, there is much agreement that current principles and procedures need to be revisited. ${ }^{35-37}$

The historical case described herein concerns ovotesticular DSD, where the amount of steroidogenic testicular tissue will determine if the affected person develops as a woman or as a man, regarding both gender and sexual characteristics. As such, this type of DSD can be viewed as a paradigm, demonstrating that the testosterone level might offer an objective parameter to separate the sexes, if required. In fact, this parameter is already implemented, in the context of sports. Athletes (46,XY and androgen sensitive) who have undergone male-to-female sex reassignment are welcome to engage in sports competitions from 2 years after the sex change, as of the Olympic Games 2004 in Athens, according to fortunate and emancipative regulations by the International Olympic Committee. ${ }^{38}$ Similarly, athletes $(46, \mathrm{XX}$ and androgen sensitive) who have undergone female-to-male sex reassignment can compete, but they will receive exogenous testosterone. For female-to-male sex-reassigned individuals receiving testosterone supplementation, a total testosterone level of around $30 \mathrm{nmol} / 1$ has been reported. ${ }^{39}$ Perhaps, one day we may witness a talented 46,XX sex-reassigned male who is able to successfully compete with $46, \mathrm{XY}$ males, thanks also to approved testosterone supplementation. Men exposed to stress and exhaustion face difficulty in maintaining their endogenous testosterone level, ${ }^{40-42}$ which might imply an advantage for 46,XX sex-reassigned males, particularly in endurance sports. Similarly, a therapeutic use exemption for long-term testosterone administration in $46, \mathrm{XY}$ men, to compensate for a secondary loss of gonadal testosterone production, might provide an advantage. The above serves to illustrate the point that current concepts and regulations regarding the relationship between sex and testosterone in sports offer room for consideration. We feel that this should be taken as a starting point to discuss the circulating testosterone level as a relevant criterion in evaluating what separates women and men in sports competitions.

The present report is not meant to provide a guideline, which would require detailed analysis of total testosterone levels in large numbers of female and male athletes in relation to possible confounding factors, and consensus meetings. Rather, we aim to contribute to an open discussion involving experts from the fields of biology, medicine, genetics, psychology, sports and ethics, to accomplish a procedure which would respect the authenticity of an adult individual's sex and gender identity. 
Note On 12 April 2011, the International Association of Athletics Federations (IAAF) announced the adoption of new rules and regulations governing the eligibility of females with hyperandrogenism to participate in women's competition, which will come into force from 1 May 2011 (http://www.iaaf.org/aboutiaaf/news/ newsid $=59746$. htmll

It appears that these new IAAF rules, as announced, are in full agreement with the viewpoint expressed in our article, which at the time of the IAAF announcement was already in press with the British Journal of Sports Medicine. We would like to emphasise that our viewpoint was composed independently from $I A A F$, and that none of the authors has been in contact with the respective IAAF expert working group

Acknowledgements The authors are very grateful to the heirs of Foekje Dillema for their frank and considerate willingness to dedicate information and materials to the present historical perspective on female athletes confronted with questioned gender issues. For the photograph of figure 1 we obtained right of use from the International Institute of Social History, Amsterdam.

Funding KNB and MK were supported by the Netherlands Forensic Institute (NFI), and the Netherlands Genomics Initiative (NGI)/Netherlands Organization for Scientific Research (NWO) within the framework of the Forensic Genomics Consortium Netherlands (FGCN).

Patient consent Obtained.

Contributors KNB and MK designed the experiments, KNB carried out the experiments, MK provided lab equipment and test materials, all authors contributed to the data interpretation, the writing of this manuscript was led by $J A G$, and all authors approved the final manuscript.

Provenance and peer review Not commissioned; externally peer reviewed.

\section{REFERENCES}

1. Kooman K. Een koningin met mannenbenen: Fanny Blankers-Koen, atlete van de eeuw (A queen with manly legs: Fanny Blankers-Koen, athlete of the century). Amsterdam/Antwerpen: LJ Veen 2003.

2. Elsas LJ, Ljungqvist $A$, Ferguson-Smith MA, et al. Gender verification of female athletes. Genet Med 2000;2:249-54.

3. Dickinson BD, Genel M, Robinowitz CB, et al. Gender verification of female Olympic athletes. Med Sci Sports Exerc 2002;34:1539-42.

4. Genel M, Ljungqvist A. Essay: Gender verification of female athletes. Lancet 2005;366(Suppl 1):S41.

5. Wilson DR. Gender vs sex. JAMA 2000;284:2997-8.

6. Simpson JL, Ljungqvist A, Ferguson-Smith MA, et al. Gender vs Sex. JAMA 2000:284:2997-8.

7. Swaab DF, Garcia-Falgueras A. Sexual differentiation of the human brain in relation to gender identity and sexual orientation. Funct Neurol 2009:24:17-28.

8. World Health Organization. What Do We Mean by Sex and Gender? http://www.who int/gender/whatisgender/en/index.html (accessed 24 March 2011).

9. Ohno S. Properties of X chromosomes. Lancet 1961;1:723-4.

10. Serrat A, García de Herreros A. Determination of genetic sex by PCR amplification of Y-chromosome-specific sequences. Lancet 1993:341:1593.

11. van Niekerk WA, Retief AE. The gonads of human true hermaphrodites Hum Genet 1981:58:117-22.

12. Krob G, Braun A, Kuhnle U. True hermaphroditism: geographical distribution, clinical findings, chromosomes and gonadal histology. Eur J Pediatr 1994;153:2-10.

13. Hughes IA, Houk C, Ahmed SF, et al. Consensus statement on management of intersex disorders. Arch Dis Child 2006:91:554-63.

14. Oakes MB, Eyvazzadeh $A D$, Quint $E$, et al. Complete androgen insensitivity syndrome-a review. J Pediatr Adolesc Gynecol 2008;21:305-10.

15. Conn J, Gillam L, Conway GS. Revealing the diagnosis of androgen insensitivity syndrome in adulthood. BMJ 2005;331:628-30.

16. Martínez-Patiño MJ. Personal account: a woman tried and tested. Lancet 2005;366(Suppl 1):S38

17. Wilson JD. Androgens, androgen receptors, and male gender role behavior. Horm Behav 2001;40:358-66.
18. Davison SL, Bell R, Donath $\mathrm{S}$, et al. Androgen levels in adult females: changes with age, menopause, and oophorectomy. J Clin Endocrinol Metab 2005;90:3847-53.

19. Hagmar M, Berglund B, Brismar K, et al. Hyperandrogenism may explain reproductive dysfunction in olympic athletes. Med Sci Sports Exerc 2009;41:1241-8.

20. Handelsman DJ, Gooren LJ. Hormones and sport: physiology, pharmacology and forensic science. Asian J Androl 2008;10:348-50.

21. Skaletsky H, Kuroda-Kawaguchi T, Minx PJ, et al. The male-specific region of the human $\mathrm{Y}$ chromosome is a mosaic of discrete sequence classes. Nature 2003;423:825-37

22. Bhasin S, Woodhouse L, Casaburi R, et al. Testosterone dose-response relationships in healthy young men. Am J Physiol Endocrinol Metab 2001:281:E1172-81.

23. World Anti-Doping Agency. Technical Document - TD2009MRPL. http://www. wada-ama.org/documents/World Anti-Doping Program/WADP-IS-Laboratories/ WADA_TD2009_MRPL_V2.0_EN.pdf (accessed 24 March 2011).

24. International Association of Athletics Federations, Medical and Anti-Doping Commission. IAAF Policy on Gender Verification, 2006. http://www.iaaf.net/mm/ document/imported/36983.pdf (accessed 24 March 2011).

25. Azziz R, Carmina E, Dewailly D, et al. Positions statement: criteria for defining polycystic ovary syndrome as a predominantly hyperandrogenic syndrome: an Androgen Excess Society guideline. J Clin Endocrinol Metab 2006;91:4237-45.

26. Rosner W, Auchus RJ, Azziz R, et al. Position statement: Utility, limitations, and pitfalls in measuring testosterone: an Endocrine Society position statement. $J$ Clin Endocrinol Metab 2007;92:405-13.

27. Wang C, Nieschlag E, Swerdloff R, et al. Investigation, treatment and monitoring of late-onset hypogonadism in males: ISA, ISSAM, EAU, EAA and ASA recommendations. Eur J Endocrinol 2008;159:507-14.

28. The Rotterdam ESHRE/ASRM-sponsored PCOS Consensus Workshop Group. Revised 2003 consensus on diagnostic criteria and long-term health risks related to polycystic ovary syndrome (PCOS). Hum Reprod 2004;19:41-7.

29. Diamanti-Kandarakis $\mathbf{E}$, Panidis D. Unravelling the phenotypic map of polycystic ovary syndrome (PCOS): a prospective study of 634 women with PCOS Clin Endocrinol (Oxf) 2007;67:735-42.

30. Basaria S. Androgen abuse in athletes: detection and consequences. J Clin Endocrinol Metab 2010;95:1533-43.

31. Kelleher S, Conway AJ, Handelsman DJ. Blood testosterone threshold for androgen deficiency symptoms. J Clin Endocrinol Metab 2004;89:3813-17.

32. Foddy B, Savulescu J. Time to re-evaluate gender segregation in athletics? Br J Sports Med 2010;Published Online First: 10 August 2010 doi:10.1136/ bjsm.2010.071639.

33. Zitzmann M. Pharmacogenetics of testosterone replacement therapy. Pharmacogenomics 2009;10:1341-9.

34. Guadalupe-Grau A, Rodríguez-González FG, Dorado C, et al. Androgen receptor gene polymorphisms lean mass and performance in young men. Br J Sports Med 2011:45:95-100.

35. Hercher L. Gender verification: a term whose time has come and gone. J Genet Couns 2010:19:551-3.

36. Wonkam A, Fieggen K, Ramesar R. Beyond the Caster Semenya controversy: the case of the use of genetics for gender testing in sport. J Genet Couns 2010:19:545-8

37. Wiesemann C. Is there a right not to know one's sex? The ethics of 'gender verification' in women's sports competition. J Med Ethics 2011:37:216-20.

38. The Stockholm Consensus on Sex Reassignment in Sports, 2003. http://multimedia. olympic.org/pdf/en report 905.pdf and http://multimedia.olympic.org/pdf/en report_904.pdf (accessed 24 Mar 2011)

39. Gooren LJ, Bunck MC. Transsexuals and competitive sports. Eur J Endocrinol 2004;151:425-9.

40. Opstad PK, Aakvaag A. The effect of sleep deprivation on the plasma levels of hormones during prolonged physical strain and calorie deficiency. Eur J Appl Physiol Occup Physiol 1983:51:97-107.

41. Lucía A, Díaz B, Hoyos J, et al. Hormone levels of world class cyclists during the Tour of Spain stage race. Br J Sports Med 2001;35:424-30.

42. Kraemer WJ, Fragala MS, Watson G, et al. Hormonal responses to a $160-\mathrm{km}$ race across frozen Alaska. Br J Sports Med 2008;42:116-20. 